\title{
Hair Restoration in Androgenetic Alopecia: Looking Beyond Minoxidil, Finasteride and Hair Transplantation
}

\author{
Sidharth Sonthalia ${ }^{1^{*}}$, Deepashree Daulatabad ${ }^{2}$ and Antonella Tosti ${ }^{3}$ \\ ${ }^{1}$ Consultant Dermatologist \& Dermatosurgeon SKINNOCENCE: The Skin Clinic \& Research Centre, Haryana, India \\ ${ }^{2}$ Department of Dermatology and STD, University College of Medical Sciences \& GTB Hospital, New Delhi, India \\ ${ }^{3}$ Department of Dermatology and Cutaneous Surgery, University of Miami Hospital, Miami, FL, USA \\ *Corresponding author: Sidharth Sonthalia, Skinnocence: The Skin Clinic and Research centre, Sushant Lok-1, Gurgaon-122009, Haryana, India, Tel: \\ +91-124-4014661; E-mail: sidharth.sonthalia@gmail.com
}

Received date: December 19, 2015; Accepted date: January 20, 2016; Published date: January 23, 2016

Copyright: $\bigcirc 2015$ Sonthalia S, et al. This is an open-access article distributed under the terms of the Creative Commons Attribution License, which permits unrestricted use, distribution, and reproduction in any medium, provided the original author and source are credited.

\begin{abstract}
Patterned hair loss $(\mathrm{PHL})$ is one of the most commonly encountered problems for dermatologists. PHL at an early age is often cosmetically unacceptable, tends to be persistent and inflicts a profound negative impact on one's quality of life. Androgenetic alopecia (AGA) affects both genders in a distinctive pattern of hair loss from the scalp (MPHL for male PHL and FPHL or female PHL). The etiopathogenesis of AGA is complex, so far the major factor emphasized to be involved has been the undesirable androgen metabolism at the hair follicle level. In this review article, we shall dwell upon the relatively newly understood pathophysiological factors behind the genesis of AGA apart from the hormonal factors like the Wnt/B-catenin pathway, follicular micro-inflammation, prostaglandin imbalance, loss of extracellular matrix and oxidative stress. Based on the sound understanding of these factors we will be elaborating upon therapies for treatment of AGA beyong minoxidil, finasteride and hair transplantation. Amongst the therapeutic options discussed include topical 5alpha reductase (AR) inhibitors like finasteride, oral 5AR inhibitor - dual receptor antagonist dutasteride, botanical 5AR inhibitors, oral anti-androgens and estrogens for FPHL like spiranolactone, drospirenone etc. Wnt/ $\beta$-catenin activators like topical valproic acid, hair stem cell based therapies, prostaglandin based therapies, tetrapeptides, nutritional and anti-oxidants and many more.
\end{abstract}

Keywords: Hair restoration; Androgenetic alopecia; Minoxidil; Finasteride; Hair transplantation

\section{Introduction}

Hair loss not only constitutes one of the most commonly encountered problems for dermatologists, it inflicts a profound negative impact on one's quality of life [1,2]. Advanced patterned hair loss (PHL), especially at an early age is often a source of depression in young adults. Androgenetic alopecia (AGA) affects both genders in a distinctive pattern of hair loss from the scalp (MPHL for male PHL and FPHL or female PHL). Bitemporal recession affects $98.6 \%$ of men and $64.4 \%$ of women; whereas mid-frontal hair loss affects nearly two thirds of women and three quarters of men over the age of 80 years [3]. Loss of hair from the vertex is typical of MPHL, encountered in majority of affected men. The hallmark of the condition is progressive and gradual miniaturization of hair follicles (HFs), accompanied by progressive decrease in the duration of anagen and reduction of anagen to telogen ratio. Additionally in AGA, there is a delay between the end of the telogen phase and the beginning of the new anagen phase; a resting phase called kenogen during which the hair follicle remains empty. The follicular miniaturization in AGA is an asynchronous phenomenon even within a follicular unit (FU); with affection of secondary follicles occurring in the initial phase and the primary follicles in the last [4]. In contrast, the miniaturization process is synchronous in alopecia areata (AA).

The etiopathogenesis of AGA is complex. The major factor involved in the pathogenesis of AGA is the undesirable androgen metabolism at the hair follicle level. Elevated activity of Type II isoform of the 5-alpha reductase (5AR) enzyme, which metabolizes testicular testosterone circulating in the blood into dihydrotestosterone (DHT) in the genetically predisposed hair follicles of the temporal and vertex regions, is the most significant factor in MPHL. Decreased aromatase activity (the enzyme that converts ovarian testosterone circulating in the blood into 17 beta-estradiol) leading to elevated local concentration of testosterone seems to be operative in FPHL [5]. Hair follicles of the temporal and vertex areas of the scalp express androgen receptors plentifully that bind to the increased local levels of DHT, resulting in shortening of anagen and progressive miniaturization of thick, pigmented terminal hair into thinner, non-pigmented vellus-like hair [6]. Finasteride (FIN), the only United States Federal Drug administration (FDA) approved oral agent for MPHL is a specific inhibitor of 5AR, type II isoform. Minoxidil (MNX), the other FDA approved topical agent (for MPHL as well as FPHL) apparently acts by increasing follicular vascularity (as a potassium channel opener), prolonging anagen and shortening telogen, and also by converting partially miniaturized (intermediate) hair follicles to terminal hair [7]. Hair transplantation, of course remains one of the best and sometimes the only therapeutic option in advanced AGA.

Essentially there is a four-fold reason to explore new therapies for AGA. Firstly, the improvement with MNX and/or FIN is limited and tends to plateau after one to two years of continuous use. The success rate of treatment for AGA barely exceeds 30\% using either of these agents; which brings the second reason to the fore, i.e., a high possibility of other pathophysiologic pathways being involved in this condition [8]. Indeed, there is now sufficient evidence supporting the role of factors other than hormones contributing significantly to the pathogenesis of AGA (vide infra). Thirdly, the sexual adverse effects (SAEs) of FIN, whether sustained actually or due to the nocebo effect [9], and the tediousness of twice-daily application of MNX often 
reduce patient compliance, necessitating the development of novel therapies. Lastly, despite the advantages of hair transplantation, many patients who are candidates for the same prefer to avoid undergoing a 'surgical' procedure for hair restoration. In this review article, we shall dwell upon the relatively newly understood pathophysiological factors behind the genesis of AGA and discuss therapies for treatment of AGA beyond minoxidil, finasteride and hair transplantation.

\section{New Horizons in the Pathogenesis of AGA}

\section{Wnt/ $\beta$-catenin pathway - A new flyspeck in androgen- mediated pathogenesis:}

The relatively recent appreciation of the role of activation of Wnt signaling for hair growth and wound healing [10] has literally unleashed an altogether different approach to stimulating hair growth. Hair follicle regeneration begins when signals from the mesenchymederived dermal papilla cells (DPC) reach multipotent epidermal stem cells in the bulge region [11]. Activation of $\mathrm{Wnt} / \beta$-catenin signaling in the epidermis leads to expansion of the stem cell compartment and skews the keratinocytes in the interfollicular epidermis and sebaceous glands (SGs) to differentiate along the HF lineage. The activation of Wnt signaling, especially Wnt10b is essential for hair follicle development, hair cycling and hair growth $[12,13]$. Wnt has been shown to be the first trigger that stimulates DPC to induce hair growth through induction and initiation of hair follicle formation, and prolongation of anagen [13]. While the initiation of HF regeneration seems to require only epidermal production of Wnt, the maintenance and growth of these hair follicles needs subsequent interaction of Wnt pathways between dermal and epidermal cells $[12,14]$. Although the exact molecular mechanisms behind Wnt-induced hair follicular stimulation to produce hair remain conjectural, activation of the Wnt/ $\beta$-catenin pathway seems to be contributory [14-16]. The importance of the Wnt/ $\beta$-catenin pathway in AGA is underscored by the recent demonstration of molecular cross-talk between androgens and the Wnt signaling in DPC, in patients with AGA. In a co-culture model with human DPC from patients with AGA and HF stem cells, Leirós et al.. demonstrated that androgens abrogate hair differentiation, evaluated by hair-specific keratin 6 expression [11]. Wnt signaling activation restored the ability of androgen-treated DPC to induce differentiation. Androgen treatment revealed a profound reduction of the cytoplasmic/total $\beta$-catenin protein ratio and upregulation of the activity of glycogen synthase kinase- $3 \beta$ in DPC, indicative of canonical Wnt pathway inhibition. Thus, it is becoming increasingly apparent that androgens deregulate DPC-secreted factors involved in normal HF stem cell differentiation via the inhibition of the canonical Wnt signaling pathway [11]. Thus, an understanding of these pathways has clearly opened a new option of targeted treatments for AGA through the modulation of the Wnt/ $\beta$-catenin pathway. This includes drugs like valproic acid and analogs like lithium chloride and beryllium chloride, which have been shown to induce hair regeneration in murine model and promote human hair growth in in-vitro culture model; and the hair stimulating complex, a bioengineered human cell-derived formulation containing Wnt7a protein that has shown promising results in Phase I human clinical trials [10, 17-19].

\section{Follicular micro-inflammation}

Follicular micro-inflammation and fibrosis are being increasingly recognized to play an important role in AGA, especially in the early phases. Several studies have reported mild to moderate lympho- histiocytic inflammatory infiltrate in the peri-infundibular region of HF taken from subjects with AGA compared with controls [8]. The term 'microinflammation' has been proposed, to differentiate the gradual, subtle, and indolent process occurring in AGA from the prominent inflammation and fibrosis characteristically seen in classical cicatricial alopecias. Morphometric studies in patients with MPHL treated with MNX showed that $55 \%$ of those with micro-inflammation had re-growth compared to $77 \%$ in those patients without inflammation and fibrosis [20].

The exact trigger for this follicular micro-inflammation remains speculative. The detection of the perifollicular infiltrate in the upper follicle near the infundibulum of HF in AGA suggests the localization of potential triggers to the peri-infundibular region; e.g. Propionobacterium sp., Malassezia sp., or other residential flora of the follicular infundibulum, antigens of whom may be involved in the generation of the inflammatory response [21]. The role of keratinocytes and Langerhans cells acting as antigen presenting cells (APC) and inducing $\mathrm{T}$ lymphocyte infiltration and proliferation mediated by various pro-inflammatory cytokines has been suggested. Further, perifollicular fibrosis (appreciable on cross-sectional scalp biopsy of scalp with AGA as 'fibrotic streamers') seems to result from cytokine mediated activation of collagenases, such as matrix metalloproteinases (MMPs) [8,21], and may end with complete destruction of the affected follicles in advanced cases. Further support for the role of micro-inflammation in AGA has come from studies that documented significantly superior results in improving hair growth with combinations of MNX with antimicrobials and/or antiinflammatory agents (like zinc pyrithione, ketoconazole, hydrocortisone, diclofenac, tea tree oil) compared with use of MNX alone [22].

\section{Prostaglandin imbalance}

The recent discovery by Garza et al. of prostaglandin D2 (PGD2) and its synthetase (PGD2S) being highly expressed in the scalp of balding men with AGA, and the temporal relationship of the increased levels of PGD2 with the initiation of miniaturization of hair follicles in mice has serious implications for developing targeted interventions for treating AGA [23]. PGD2 apparently inhibits hair growth by binding to only one of its two receptors i.e. DP-2, located in the outer root sheath of the HF $[23,24]$. The opposing role of prostaglandin E2 (PGE2), a known hair growth promoter was additionally confirmed by detection of significantly increased levels of PGE2 in hairy non-balding scalp. This discovery emphasizes on the role of balance between PGE2 and PGD2 in controlling hair growth, dysregulation of which may be responsible for hair loss in AGA. Logical extrapolation would favor the therapeutic role of supplemental PGE2, and inhibitors of PGD2 signaling by DP- 2 antagonists such as indole acetic acids, phenyl acetic acids or tetrahydroquinolines $[25,26]$.

\section{Oxidative stress}

Apoptosis of HF cells followed by early onset of the catagen phase by lipid peroxides that generate free radicals has been demonstrated by Naito et al. [27]. In the DPC culture study of Bahta et al., balding DPCs not only demonstrated slower in-vitro growth (compared to nonbalding scalp DPCs) but additionally showed increased nuclear expression of markers of oxidative stress and DNA damage including heat shock protein-27, super oxide dismutase, catalase, and p16(INK4a)/pRB [28]. These findings further suggest that DPCs of androgenetic HFs are more sensitive to environmental oxidative stress. 
Indeed, pro-oxidant effects are suggested as the major mediators of smoking and ultraviolet light induced exacerbation of AGA [21].

\section{Loss of extracellular matrix (ECM)}

In recent past, the loss of extracellular matrix (ECM) proteins in the follicular bed contributing to progressive reduction in the size of the hair follicle and loss of hair anchoring has gained attention as an additional pathogenetic factor for AGA [29]. The ECM is the extracellular part of tissue that usually provides mechanical and structural support to the follicle cells. An appropriate amount of ECM proteins, specifically collagen type III, laminin and collagen VII is vital to provide a good anchorage of the hair shaft to the bulb [30]. In addition, the ECM components regulate metabolic functions of the cells surrounded by the matrix by - promoting anchorage of hair shaft in the HF, and modulating cell growth by binding and retaining growth factors. Replenishment and re-modeling of these ECM components by dermal fibroblasts is thus essential to ensure the integrity of ECM and strong anchorage of the developing HF with the bulb. Results from early DPC culture based studies by Randall et al. have implicated an indirect role of androgens in altering the production of regulatory substances such as growth factors and/or ECM components acting via the cells of the dermal papilla, which is their primary target [31].

In AGA, the naturally occurring tetrapeptide acetyl-N-Ser-Asp-LysPro (AcSDKP), a potent angiogenic factor has been demonstrated to not only upregulate the synthesis of epidermal keratins, but also ECM associated components including collagen III as well as the glycoaminoglycans (GAGs). In the ex vivo-cultured hair follicles, AcSDKP were found to promote hair shaft elongation and induce morphological and molecular modifications culminating into stimulation of hair growth [32]. Biomimetic peptides such as acetyltetrapeptide- 1 and 3 , and their combination with botanical extracts like Trifolium pratense flower extract, or biochanin-A (an isoflavone derived from red clover), enhance hair growth primarily by stimulation of ECM protein synthesis in the vicinity of the hair follicle [29]. Figure 1 summarizes salient points regarding these relatively newer pathophysiological mechanisms implicated in AGA.

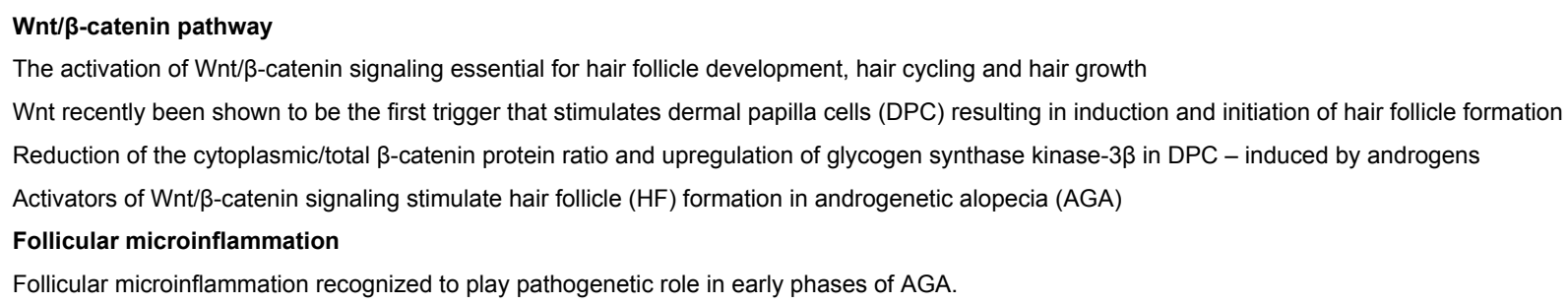

Compared to non-balding scalp DPCs, the balding DPCs not only demonstrated slower in-vitro growth but aalso showed increased nuclear expression of markers of oxidative stress and DNA damage including heat shock protein-27, super oxide dismutase, catalase, and p16(INK4a)/pRB.

Pro-oxidant effects by free radical are suspected to be the major mediators of smoking and ultraviolet light induced exacerbation of AGA.

Figure 1: Insights from the recently understood pathogenesis of AGA.

\section{Newer Drugs for Hair Growth (Other than Topical MNX and Oral FIN)}

Topical minoxidil and finasteride ( $5 \alpha$ reductase type II inhibitor) are the only FDA approved treatments for MPHL. Both agents arrest progression of hair loss and stimulate partial hair regrowth. Several other drugs are also used off-label and a plethora of novel treatments with partially substantiated hair growth claims are making inroads in trichologists' prescriptions. Thus, the knowledge of these alternative drugs, their mechanism, dose protocol and adverse effects is exigent for today's practicing dermato-trichologist. Figure 2 summaries salient points regarding major pathogenetic mechanisms. 
Citation: Sonthalia S, Daulatabad D, Tosti A (2016) Hair Restoration in Androgenetic Alopecia: Looking Beyond Minoxidil, Finasteride and Hair Transplantation. J Cosmo Trichol 2: 1000105. doi:10.4172/2471-9323.1000105

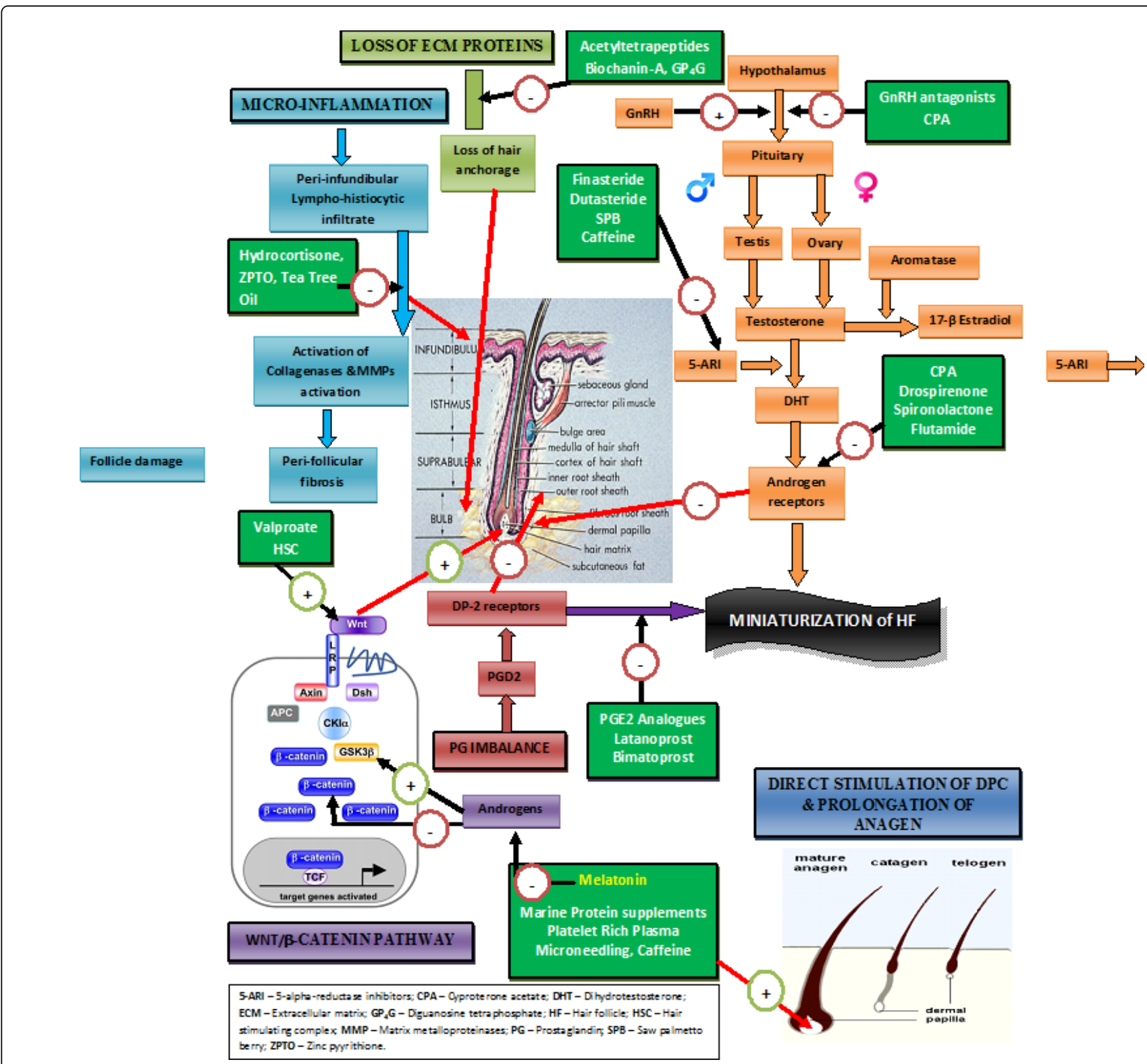

Figure 2: Schematically outlines of the major pathogenetic mechanisms involved in AGA and important treatment options targeting the same.

\section{Hormone Antagonists and Hormone Response Modulators}

\section{Topical 5AR inhibition}

The use of anti-androgens in a topical formulation has always been an attractive proposition, since it is expected to deliver some efficacy of the oral drug, with minimal risk of systemic adverse effects. In a randomized single center, open-label, parallel-group, exploratory study conducted in 24 healthy men with AGA subjects received either multiple scalp applications of the topical solution of FIN (0.25\%) twice-a-day or oral FIN $1 \mathrm{mg}$ once-a-day for 7 days. A strong and comparable inhibition of plasma DHT was observed in both the groups, but the serum levels of finasteride were significantly lower with the topical application group [33]. The investigators, however did not measure the scalp DHT levels. In a retrospective assessment of 50 male patients aged 20-40 years with AGA, who had initially been treated with topical MNX and oral FIN for a period of two years, and after which the oral FIN was replaced with combination of topical 5\% MNX fortified with $0.1 \%$ FIN, $84.44 \%$ maintained a good hair density with topical combination therapy. Thus, topical finasteride can be considered for hair density maintenance after initial improvement with oral finasteride, thereby obviating the indefinite use of oral finasteride [34].

\section{Oral 5AR inhibition - Dual receptor antagonist dutasteride}

In contrast with FIN, dutasteride, is a dual 5AR inhibitor and is approximately 3 times more potent than FIN at inhibiting type II 5AR and almost 100 times more potent at inhibiting type I isoenzyme [35]. The effect of dutasteride is dose dependent. A phase II randomized 
placebo-controlled study of dutasteride versus finasteride showed superiority of $2.5 \mathrm{mg}$ of dutasteride over $5 \mathrm{mg}$ finasteride in improving scalp hair growth in men aged 21-45 years.[36]. The onset of hair growth was also earlier in the dutasteride group. Improvement of hair loss with dutasteride $0.5 \mathrm{mg}$ has also been demonstrated in a lady who failed to show any response to finasteride [37]. It has been safely administered in women with FPHL in doses of $0.15 \mathrm{mg}$ per day for three years [38]. Side effects including decreased libido, impotence and gynecomastia are slightly higher with dutasteride than with FIN [36]. In addition, the nocebo effect, described for FIN [9] is also likely to be encountered with dutasteride in the more educated and internet-savvy patients. The long serum half-life of 4 weeks of dutasteride results in persistent suppression of DHT level even after dutasteride is ceased. Thus, patients taking dutasteride should not donate blood until at least 6 months after stopping their medication [36]. Currently, dutasteride $0.5 \mathrm{mg}$ dose is FDA approved for the treatment of benign prostatic hyperplasia while its use in MPHL and FPHL remains "off-label". It is worth trying in patients with advanced PHL and when FIN delivers sub-optimal.

\section{Botanical 5AR inhibitors}

Owing to the SAEs associated with FIN and dutasteride, extracts of herbs with 5AR inhibitory effect have been explored as an alternative. Saw palmetto berry (SPB) extract derived from the berry of the American dwarf tree (Serenoa repens, Sabal serrulata) is the most popular phytotherapeutic agent used in the treatment of AGA as well as benign prostatic hypertrophy $(\mathrm{BPH})$. The extracts from the ripe berries of saw palmetto contain various phytosterols (e.g. $\beta$-sitosterol), fatty acids, $\beta$-carotene and polysaccharides. SPB is being promoted as the 'herbal side-effect-free version of finasteride) for the treatment of AGA. SPB acts as a multi-site inhibitor-cum-blocker of DHT [39]. It blocks approximately $50 \%$ of the binding of DHT to ARs in the target cells. It also blocks the nuclear uptake of DHT in target cells, and strongly inhibits the action of the enzyme 5AR thereby reducing the conversion of testosterone to DHT. Additionally, saw palmetto increases activity of the $3 a$-hydroxysteroid-dehydrogenase, the enzyme responsible for the metabolism of DHT into androstanediol, a weaker androgen.

While the principle molecules responsible for the aforesaid actions of saw palmetto are phytosterols, their activity is enhanced in their conjugated state with fatty acids. $B$-sitosterol has been suggested to result in local reduction of testosterone (the substrate for formation of DHT) in the microenvironment of 5AR active tissues such as the prostate and the hair follicle. Thus, the pharmacodynamics of saw palmetto differ from that of FIN in the following ways 1) dual inhibitor of both isoforms of 5AR 2) competitive as well as non-competitive inhibition of the enzyme, and 3) multi-site effect, in addition to 5AR inhibition. In terms of side-effects, multiple trials on BPH have consistently shown SPB to be free of the SAEs typical of FIN and dutasteride [40]. In a placebo-controlled, double-blind study conducted in 26 healthy men aged 23-64 years with mild to moderate AGA, subjects were randomly assigned to receive the active oral softgel (consisting of saw palmetto extract $200 \mathrm{mg}$ and $ß$-sitosterol $50 \mathrm{mg}$ as the major ingredients, with additional components to increase the bioavailability such as lecithin, inositol, phosphatidylcholine, niacin, and biotin) or a matching placebo; one softgel twice daily in both the groups for 21 weeks duration. Out of the 26 subjects, 19 completed the study. Treatment efficacy at the final visit as per the investigative staff assessment of change in the patient's scalp hair growth from baseline ('improved') was reported to be $60 \%$ vs $11 \%$ in the study group vs placebo group respectively [41]. The adverse effects in the study group were mild and transient. Though botanical 5AR inhibitors lack the SAEs of FIN, their efficacy in improving hair growth in AGA is inferior to their synthetic counterparts. This has been revealed in a 2-yr long open label study of 100 male patients with AGA, in which the hair growth score was higher in the group that received FIN $1 \mathrm{mg}$ every day, compared to the group that received Serenoa repens $320 \mathrm{mg}$ daily for the same period. Moreover, the effect of Serenoa repens over the front area was inferior to that of FIN [42]. Thus, larger and genderspecific trials with better defined efficacy end points are needed to discern the role of saw palmetto as a treatment option for AGA.

\section{Oral anti-androgens and estrogens for FPHL}

Androgen-dependent oral drugs for FPHL include 5AR inhibitors and anti-androgens. Owing to their propensity to cause feminization of the male fetus, they are contra-indicated in pregnant women. Use of these drugs in combination with oral contraceptive pills (OCPs) offers two advantages. Not only do they provide effective contraception to prevent teratogenic effects of anti-androgens in a woman of reproductive age group, the estrogen component of the pill has additional hair growth stimulatory effects. It has been suggested that estrogens act both directly (by prolonging the anagen phase acting via follicular estrogen receptors) and indirectly (by increasing sex hormone binding globulin (SHBG) production, which reduces androgen levels by binding to them) [7,43]. Cyproterone acetate (CPA) blocks androgen receptors and inhibits gonadotropin-releasing hormone (GnRH). In many countries including India, it is available in combination with estradiol as an OCP [44]. The beneficial role of CPA seems to be greater in patients with evidence of hyperandrogenism. In two studies, combination therapy of CPA with estradiol resulted in significant decrease in shedding and thinning of hair in patients with FPHL $[45,46]$. Spironolactone, another anti-androgen often used for treating hirsutism and acne, has also been found to be comparably efficacious to CPA in a trial involving $80 \mathrm{FPHL}$ patients [46]. The dose used was $200 \mathrm{mg}$ daily. Drospirenone, a $17 \alpha$ spironolactone derivative possesses progestagenic, anti-androgenetic, and antialdosteronic activities, but is devoid of fluid retention property. Administered in a dose of $3 \mathrm{mg} /$ day in combination with $30 \mu \mathrm{g}$ of ethinylestradiol during a 21-day cycle, it has become a favoured pill for women with PCOS and is expected to have beneficial effects in FPHL [7]. Flutamide, a selective anti-androgen has found to be effective in FPHL when given for at least a year in dose of $250 \mathrm{mg} /$ day [47]. Two randomized studies reported greater improvements with flutamide than spironolactone, FIN, and CPA $[46,48]$. Unfortunately, the adverse effects of this drug, especially dose-related severe hepatic dysfunction (seen in upto $3 / 10,000$ patients) make it an unpopular choice for many trichologists.

\section{Wnt/B-catenin Activation}

\section{Topical valproic acid}

Valproic acid (VPA), a widely used antiepileptic, is known to activate the Wnt/ $\beta$-catenin pathway, which is associated with hair growth cycle and anagen induction $[17,18]$. After initial encouraging results from murine-model based studies, a recent randomized, double-blind, placebo-controlled clinical trial was conducted in 40 men with AGA of which 27 completed the trial. Patients with moderate AGA received either VPA (8.3\%) or placebo spray for 24 weeks. Phototrichogram analysis was employed to evaluate the primary end-point for efficacy, i.e., change in hair count during 
treatment. The mean change in total hair count was significantly higher in the VPA group than in the placebo group [49]. Adverse effects were mild and self-limited.

\section{Hair stimulating complex (HSC)}

Hair stimulating complex (HSC) is a bioengineered human cellderived formulation containing Wnt7a protein, epidermal growth factors and follistatin, manufactured from naturally secreted growth factors, proteins and other synergistic bioproducts that are derived from culture of newborn cells grown in an oxygen-deficient embryonic environment. In phase I trial, intradermal application of $0.1 \mathrm{cc}$ of HSC resulted in significantly increased hair shaft thickness, hair density and number of total terminal hair without any significant adverse effects, compared with placebo at 12 weeks [19]. Interestingly, the effect was maintained after 1 year of treatment at the HSC-treated sites. Phase II trials are ongoing to gather more evidence in favour of HSC as a viable therapeutic modality for PHL.

\section{Stem cell-based therapies}

Cross-species injection of antlerogenic stem cells in rabbits has demonstrated increased number in hair follicles in the treated sites. Moreover, these xenogenous stem cells induced an insignificant immune response when compared with vehicle alone [50]. This breakthrough, despite the need for substantiation with more studies, has raised the possibility of using purified animal stem cells to promote hair growth in humans [10]. Attempts to generate a follicular germ by combining stem cells and dermal papillae followed by scalp implantation of the germ have also proved fruitful with growth of a viable hair follicle that was able to repeat the hair cycle, mingle with the surrounding tissues and achieve piloerection [51]. These results invigorate the possibility of creating a functional hair follicle from follicular stem cells, i.e., bioengineering hair for transplant. Trials are ongoing to evaluate the possibility of creating new hair follicles by injecting autologous dermal and/or epidermal cells.

\section{Prostaglandin-Based Therapies}

\section{Prostaglandin and prostamide analogues}

Although drugs that block PGD2 signaling or enhance PGE2 are under trial for evaluation of their efficacy and safety in AGA, other prostaglandins also have therapeutic effects. The prostaglandin F2 $\alpha$ analogue latanoprost, and prostamide F2 $\alpha$ analogue bimatoprost, commonly used in treating glaucoma were serendipitously discovered to be promoters of hair growth of eyelashes and eyebrows. They result in hair growth through modulatory action on the dermal papilla that results in induction of the anagen phase in telogen hair follicles. Bimatoprost is the only FDA-approved topical for hypotrichosis of the eyelashes [52]. In anecdotal reports and few studies, these analogues have resulted in modest hair regrowth in alopecia areata, involving the eyebrows and eyelashes. They are also used for cosmetic enhancement of eyelashes. However, the use of these agents in PHL lacks robust evidence. Following encouraging results from animal model-based studies, a randomized comparison study that evaluated the use of topical latanoprost $0.1 \%$ versus placebo (solutions applied daily to two minizones of the scalp) in 16 men with Hamilton II-III patterned alopecia revealed a significant increase in hair density of both terminal and vellus hair on the latanoprost-treated site at 24 weeks, compared to baseline and to the placebo-treated site [53]. Fifty percent were defined as having a "good clinical response" (treatment better than placebo in at least two of the study criteria). Adverse events were limited to folliculitis, erythema, and burning sensation on application. In contrast, scalp injections of bimatoprost $0.03 \%$ weekly for 12 weeks and then biweekly for 4 weeks attempted in a 59-year-old female with FPHL failed to improve the condition [54]. Thus, it is premature to comment on the efficacy of this group of drugs in PHL at present.

\section{Direct Stimulation of Stem Cells and Dpcs}

\section{Marine protein supplements}

Oral marine protein supplements (MPS) have been used for more than 15 years as nutritional enhancers of hair growth in AGA. Viviscal ${ }^{\circ}$ (Hair Nourishment System; Lifes2good, Inc., Chicago, Illinois), originally marketed under the brand name Hairgain ${ }^{\oplus}$ [Parexel Medstat AS, Lillestrøm, Norway]) contains AminoMar $\mathrm{C}^{\mathrm{m}}$ marine complex as its most active principle, a proprietary blend of shark and mollusk powder [55,56] Additional contents include an organic form of silica derived from Equisetum sp. (horsetail), vitamin C derived from Malpighia emarginata (acerola cherry), microcrystalline cellulose (E460), natural orange flavor, magnesium stearate, hypromellose, and glycerol [56]. Several studies, including randomized, controlled trials have demonstrated the efficacy of Viviscal in the treatment of AGA in men $[55,57,58]$. Significant improvements, in terms of the physicianassessed terminal hair counts as well as patient-perceived benefits in hair volume, scalp coverage, and thickness of hair shafts have also been reported in multiple double-blind, placebo-controlled studies evaluating the efficacy of Viviscal supplement (given orally twice-a-day for 3 months to 6 months) in women with self-perceived thinning hair $[56,59,60]$. No AEs were reported in any study. Shell fish allergy is a contraindication for this neutraceutical. The mechanism of Viviscal seems to be the enhancement of proliferation of DPCs. It has been postulated that Viviscal increases the alkaline phosphatase levels, a key marker of anagen phase of the hair cycle, in DPCs [59]. Summarizing from the above results, Viviscal may be an effective treatment option both alone as well as a part of a comprehensive hair restoration plan, e.g. in combination with MNX and/or FIN.

\section{Platelet rich plasma}

Platelet-rich plasma (PRP), an autologous preparation of plasma with $>1,000,000 / \mu \mathrm{L}$ platelets is gaining popularity across the globe as an adjuvant treatment for PHL and to circumvent or delay the need for hair transplantation. The platelet related growth factors (such as platelet-derived growth factor (PDGF), transforming growth factor (TGF), vascular endothelial growth factor (VEGF), fibroblast growth factor (FGF), epidermal growth factor (EGF), and insulin-like growth factor (IGF-1)) improve hair growth by multiple mechanisms stimulation of the bulge stem cells and dermal fibroblasts, proliferation of dermal papilla cells, prolongation of anagen, and delaying the progression into catagen [61]. There are many important factors that determine the ultimate efficacy of the therapy - e.g., the anti-coagulant used in the collection tubes, centrifuge machine parameters (rotation speed and total time), single-spin or double-spin method, manual preparation or use of commercially available kits, temperature control, addition of platelet activators etc. And more studies are warranted to crystallize these concepts. The only adverse effect with PRP is the procedure related pain and temporary scalp swelling. It should be performed under topical anesthesia. Use of locoregional scalp blocks 
are an alternate option to make the procedure painless, but needs training.

In a prospective cohort study that enrolled 18 males and 2 females with PHL, PRP prepared by single-spin method in Regenlab SA kit was injected in the androgen-related areas of scalp [62]. Three treatment sessions, once-every-3-weeks and a booster session at 6 months were delivered. At 3 months, reduction of hair loss was significant and hair density reached a peak at 3 months Improvement continued till one year of the last treatment. Patients were satisfied with a mean result rating of 7.1 on a scale of 1-10. In a recent randomized, evaluator-blinded, placebo-controlled, half-head group study compared hair regrowth with PRP versus placebo with the aid of computerized trichograms. PRP, prepared from a small volume of blood, was injected on half of the selected patients' scalps with PHL. The other half was treated with placebo. Three treatments administered at 30-day intervals protocol could be analyzed for 20 patients. Patients were followed for 2 years. Of the 23 patients were enrolled, 3 were excluded. At the end of the 3 treatment cycles, a significant improvement in the mean number of hair (mean increase of 33.6 hair in the target area) and a mean increase in total hair density (of 45.9 hair per $\mathrm{cm}^{2}$ ) was observed compared with baseline values [63]. No side effects were noted. In long term follow up, out of 20 patients, 4 (20\%) reported progressive hair loss, which was more evident 16 months after the last treatment. However, one must be aware of the finer art of preparing and injecting PRP to optimize patient outcomes. Readers are advised to refer to the article by Dhurat and Sukesh for further reading on this aspect [64].

\section{Microneedling}

Microneedling involves the use of a microneedle-tipped instrument, most commonly a dermaroller or a dermapen, available in models with different or adjustable needle depths (usually ranging from 0.2-3.0 $\mathrm{mm}$ ). Traditionally used for facial acne scars, facial rejuvenation, open pores and striae (owing to its collagen stimulation and remodeling effects), microneedling has recently been shown to enhance expression of hair-related genes and stimulation of hair in mice by Jeong et al. and Kim et al., $[65,66]$. A randomized evaluator blinded trial by Dhurat et al. evaluated the effect of microneedling in 100 patients with MPHL (grade III vertex or IV), with the Microneedling Group offered weekly microneedling sessions along with twice daily 5\% MNX lotion, and the other group given only 5\% MNX lotion twice daily. Dermaroller-MNX treated group was statistically superior to MNX-alone treated group in promoting hair growth in men with AGA for all 3 primary efficacy measures of hair growth, including the mean change in hair count at week 12 (91.4 vs 22.2 respectively), investigator evaluated visual analogue scale scoring, and percentage of patients reporting more than $50 \%$ improvement ( $82 \%$ vs $4.5 \%$ ) [67]. The hair re-growth induced by microneedling is thought to result from the controlled wounding induced by the dermaroller and the postulated mechanisms include release of growth factors like PDGF and EGF, direct activation of stem cells in the hair bulge area, and increased expression of hair growth related genes including $\beta$-catenin, Wnt3a, and Wnt10 b [65-67].

\section{Stimulation of ECM components}

\section{Tetrapeptides}

The naturally occurring tetrapeptide AcSDKP, a potent angiogenic factor was recently shown to stimulate the growth of human keratinocytes, fibroblasts and follicle DPC. In the study by Hajem et al., topical treatment of ex vivo cultured skin explants with 10 M AcSDKP not only increased the thickness of the epidermis and upregulated keratin synthesis, it also stimulated production of ECM components including fibronectin, collagen III and IV, as well as the glycoaminoglycans (GAGs) [32]. In the ex vivo-cultured hair follicles, AcSDKP promoted hair shaft elongation and induced morphological and molecular modifications, suggestive of hair growth induction. In a randomized placebo-controlled study by Loing et al. conducted in 30 volunteers with early AGA, daily application of a cosmetic active ingredient prepared by combining Trifolium pratense flower extract and a biomimetic peptide for 4 months yielded a significant increase in anagen hair count $(+13 \%)$, and the anagen/telogen $(\mathrm{A} / \mathrm{T})$ ratio $(+46 \%)$ over baseline, compared to application of placebo [29]. The postulated mechanisms for hair growth stimulation include stimulation of ECM protein synthesis, inhibition of $5 \mathrm{AR}$ activity, and reduction of follicular micro-inflammation.

\section{Diguanosine tetraphosphate (GP4G)}

In the study by Severino et al., the effects of GpG formulation, a liposomic solution of Artemia salina extract, on hair follicle structures were evaluated. A $50 \%$ increase in hair length and a 30\% increase in the number of DPC were observed [68]. The mechanism seemed to be an increase in skin blood vessels and fibroblast activation modified collagen arrangement in dermal tissues. At the molecular level, cellular activation induced by GpG evidenced by a $38 \%$ increase in the intracellular ATP concentration and increases in the intracellular concentration of tri- , di- , and monophosphate nucleosides, in two cell culture lines - Hela and fibroblast cells. Thus GpG promises to be a novel option worth further exploration for hair regrowth in AGA.

\section{Nutritional and antioxidant therapy}

In the past decade an increasing number of reports have provided support for nutraceuticals as effective and safe treatment options for hair loss in general. Furthermore, there seems to be a growing trend towards supplementation compared with prescription or over-thecounter (OTC) medications. Isolated reports have evaluated the influence of various dietary supplements such as millet extracts, biotin, pantothenic acid and other B-complex vitamins, minerals like zinc and iron, omega- 3 and omega- 6 fatty acids, and anti-oxidants like lycopene in hair loss of various origins with variable results. However, the studies have seldom focused on their efficacy in AGA.

\section{Biotin}

Biotin, an essential vitamin is involved in vital physiological functions like fatty acid synthesis, amino acid catabolism, and gluconeogenesis. Additionally, it functions as a coenzyme for mitochondrial carboxylases in hair roots. Absorption of biotin requires the release of biotin from foods and biotin-containing peptides, affected by the biotinidase (BTD) enzyme. An adequate intake (AI) of $30 \mu \mathrm{g} /$ day has been suggested for adults. Genetic biotinidase deficiency, results in hair loss, in addition to a variety of systemic symptoms such as seizures, mental retardation, dermatitis, and aciduria, amongst others [69]. Important causes of acquired biotin deficiency include anticonvulsant therapy (especially valproate), intestinal malabsorption and excessive alcohol consumption. Alopecia is a common adverse effect of valproic acid, the pathogenesis of which remains controversial. While earlier studies implicated reduced activity of BTD leading to biotin deficiency as the cause of valproate-induced hair loss, newer studies have refuted this theory $[70,71]$. Irrespective of 
the effect of valproic acid on serum biotin levels or BTD activity, reversal of alopecia has been reported in few patients who were on valproic acid therapy, with oral biotin $(10 \mathrm{mg} /$ day $)$ administration. $[71,72]$. Although robust evidence favouring the role of oral biotin in arresting hair loss or stimulating regrowth is lacking, it remains one of the most prescribed nutritional supplement for any kind of hair loss. Biotin is also a frequent component of hair mesotherapy solutions. However, there is a clear paucity of any evidence based on robust research favoring the role of biotin in treatment of AGA.

\section{Zinc}

The relation between zinc deficiency and hair growth has been a subject of debate for the past three decades. Zinc is a known potent inhibitor of hair follicle regression, and also accelerates hair follicle recovery [73]. Although, there have been arguments refuting the relationship between zinc and hair loss [74], frank zinc deficiency or at least levels lower than control groups have indeed been documented in almost all forms of non-cicatricial alopecia. Although, alopecia areata (AA) and telogen effluvium (TE) have been documented to be more associated with low zinc levels $[75,76]$, in a recent study, zinc levels lower than the control group have also been documented in AGA [77]. In this case control study by Kil et al. that included 312 patients with AA, MPHL, FPHL and TE, in each category of hair loss, the serum zinc concentration was significantly lower than that of the control group. This included 161 patients of AGA (84 with MPHL and 77 with FPHL). Expectedly, the ratio of the patients with serum zinc concentration lower than the cut-off of $70 \mu \mathrm{g} / \mathrm{dL}$ was significantly high only in the AA group [77]. Zinc is also known to have some 5AR inhibitory activity [78]. In conclusion, it is not surprising that zinccontaining supplements have become a routine prescription by trichologists for AGA patients as well.

\section{Omega 3 fatty acids and antioxidants}

In a recent randomized, comparative study conducted in 120 otherwise healthy female subjects with FPHL, compared to placebo, a nutritional supplement containing omega $3 \& 6$ acids and antioxidants given for 6-months resulted in statistically significant and superior improvement in hair growth parameters including photograph assessment, reduction in telogen hair percentage, and increment in non-vellus anagen hair [79]. Subjective evaluation by the women in the supplemented group mirrored the objective results with reduction in hair loss reported by $89.9 \%$, improvement in hair diameter by $86.1 \%$ and hair density by $87.3 \%$.

\section{Miscellaneous}

Dietary supplements are popular over-the-counter products used for hair loss by patients themselves. These supplements contain combinations of amino acids like L-cystine, L-lysine, L-methionine, vitamins like biotin, calcium pantothenate and thiamine, minerals like iron and zinc, and other substances such as Brewers yeast, in different proportions. Oral supplementation with l-cystine, pantothenic acid, thiamine nitrate, and medicinal yeast has been shown to increase the anagen rate in apparently healthy women with telogen effluvium in a placebo-controlled study [80]. But none of these nutreceuticals have been tested for efficacy in AGA patients. Since their general mechanism of action seems to be induction of anagen, the use of these multivitamin-mineral-antioxidant cocktail tablets/capsules has been extrapolated as an adjuvant therapy in patients with AGA as well, despite lack of evidence of efficacy in this particular type of alopecia.

\section{Other Potential Therapies for AGA}

\section{Officinalis plant extracts - Enhancing microvascular supply of DPC}

The physiological activity of the pilosebaceous unit is linked to its local microcirculatory system [81]. The anagen phase is accompanied by angiogenesis. A recently launched commercial hair serum containing extracts from 9 Officinalis plants: Carthamus tinctorius, Prunus persica, Zingiber officinalis, Panax ginseng, Salvia officinalis, Cuscuta epithimum, Carum petroselinum, Angelica archangelica, Capsicum annuum has been suggested to be a hair growth stimulator for TE, AA as well as AGA. The primary mechanism of action seems to be an increase in the dermal papillary blood flow and nutrients supply, with additional antioxidant and hydrating effects $[81,82]$. In the study conducted by Gori et al. in 46 subjects with AGA ( 40 males, 6 females), treated with the hair serum containing officinalis plant extracts, oncea-day for 3 months, 25 (54\%) showed clinical signs of hair follicle reactivation (anagen phase), with an initial or an appreciable regrowth of terminal hair [82]. The local tolerance and cosmetic acceptance was rated good by the users.

\section{Caffeine}

Caffeine is evolving as a promising candidate for hair growth stimulation. It possesses two activities of relevance for hair growth - Indirect, via 5AR inhibition and direct, by stimulation of hair growth parameters. Employing the hair organ culture model wherein hair follicles from the vertex area of male AGA patients were cultivated, Fischer et al. demonstrated that caffeine in concentrations of $0.001 \%$ and $0.005 \%$ not only counteracted the testosterone-induced hair follicle growth suppression, but also induced significant follicular growth independently [83]. In their next study published recently, Fischer et al. elaborated on caffeine's in-vitro effect at the cytokine level in hair follicles cultivated from both men and women with AGA. Caffeine enhanced hair shaft elongation, prolonged anagen duration and stimulated hair matrix keratinocyte proliferation, with better responses observed in female HFs [84]. Protein expression of TGF- $\beta 2$ was reduced and IGF-1 increased in the matrix cells as well as outer root sheath (ORS) keratinocytes in the HFs of both genders. With discovery of such growth-promoting effects of caffeine on human HFs, the molecule has already found its way as a component of multiingredient shampoos as well as some OTC as well as prescription hair growth enhancing solutions.

Melatonin

Melatonin, the hormone secreted by the pineal gland is known to have potent antioxidant activity. It acts as a direct radical scavenger [21]. Melatonin's effects on cell growth regulation have been shown in human keratinocytes [85]. The antioxidative effects of melatonin have been found to prevent UV-induced erythema in healthy humans, prevent cell death of UVR irradiated leukocytes and have been postulated to be instrumental in counteracting the detrimental effects of environmental stressors on the aging-related parameters of skin and hair $[86,87]$. Extensive research work by Fischer et al. has revealed startling facts about the high potential of melatonin as a hair growth agent. Human hair follicles have been shown to synthesize melatonin and express melatonin receptors $[88,89]$. Human anagen hair follicles cultivated in vitro in a culture medium with a melatonin concentration of $30 \mu \mathrm{M}$ resulted in a significantly faster rate of hair follicle growth compared to the culture medium alone. [90]. Currently, MEL receptors have been identified primarily in the root sheath of the hair, and have 
been postulated to affect hair growth via receptor-mediated influence over the hair root sheaths. The hair growth effect of MEL may also involve interaction with androgens and estrogens and their receptors, as evidenced by the effects of MEL on inhibiting prostate enlargement. Antiandrogenic effects of MEL on hair follicles include prolongation of the hair cycle and decreased miniaturization.

It seems to be a promising candidate for halting hair loss and induce growth in general hair loss as well as AGA, owing to its anti-oxidative and antiandrogenic properties. Topically applied cosmetic hair solution with $0.0033 \%$ melatonin content has been explored in many studies to evaluate its efficacy in AGA in both the genders. In a detailed analysis of five clinical studies of MEL on hair loss, Fischer et al. observed positive effects of topical MEL solution in the treatment of AGA with good tolerability [91]. These studies included both men and women with early-stage AGA as well as generalized hair loss. Significant reduction in the percentage of patients with a 2- to 3-fold positive hair-pull test, reduction of the overall severity of alopecia and significant increases in hair density were observed in these studies. The duration of MEL application ranged from 3-6 months and efficacy assessment was done by different methods in different studies including questionnaires completed by investigators and patients, hairpull test, and digital software-supported epiluminescence technique (TrichoScan) treatment for AGA. Pharmacodynamics under oncedaily topical application in the evening showed no significant influence on endogenous serum melatonin levels.

\section{Topical roxithromycin}

Roxithromycin, a macrolide antibiotic has recently been explored for AGA based on its properties of inhibition of apoptosis of keratinocytes (via suppressing the production of oxygen reactive species) and suppression of the AR in human dermal fibroblasts $[92,93]$, with around $58 \%$ of the 13 men with AGA developing increase in hair shaft thickness, with no side effects following 6 months use of 3-5 $\mathrm{mL}$ of a $5 \%$ roxithromycin solution daily compared to the control group in a randomized double-blinded trial [94].

\section{Low-level laser/light therapy (LLLT)}

Since the discovery of hypertrichosis as a possible paradoxical sideeffect of laser or light-based treatments for hair reduction in 2002 with intense pulsed light therapy, this phenomenon has been estimated to occur in $0.6 \%$ to $10 \%$ of patients treated with all laser types, particularly when low fluences are used [95,96]. The suboptimal fluencies, although too mild to induce thermolysis, are high enough to stimulate follicular growth. The hypothesized mechanisms of action of LLLT are increased adenosine tri-phosphate (ATP) production, modulation of reactive oxygen species (ROS), and induction of transcription factors. Cytochrome-c oxidase (COX) has been proposed to be the cellular chromophore, with absorption peaks in the near infrared light [97]. A complex biochemical process ensues following the light-chromophore interaction leading to release of NO, which further results in cellular proliferation, increased tissue oxygenation, and modulation in the levels of cytokines and growth factors.

Devices based on the principle of LLLT include laser combs (e.g., the US-FDA approved HairMax Laser Comb ${ }^{\circ}$, available in three models with 7, 9 and 12 diode-beams per comb) and machines with helmet-like laser hoods. In a company-sponsored study of 110 male patients, treatment with the HairMax Laser Comb apparently resulted in significant increase in mean terminal hair density when compared to a sham device [98]. Based on the favorable outcome of LLLT on hair growth in an independent blinded study with seven patients, and anecdotal experiences, a consensus paper by hair loss experts suggested that while LLLT employing $650-900 \mathrm{~nm}$ wavelengths at 5 $\mathrm{mW}$ may be an effective and safe treatment option for patients with AGA, more controlled, peer-reviewed studies validating current devices were necessary [99-101]. In a 24-week, randomized, doubleblind, sham-device-controlled trial, Kim et al., reported an increase of hair density with the use of LLLT [102]. In a retrospective observational study of 32 patients (21 female, 11 male) with AGA, treated with the $655 \mathrm{~nm}$-HairMax Laser $\mathrm{Comb}^{\circledR}$, significant improvement was observed in 8 , showed significant, moderate improvement in 20 , and no improvement in 4 , with no adverse reactions reported in any patient [97]. Improvement was observed as early as 3 months and was sustained up to a maximum observation time of 24 months. Combination of LLLT with MNX and/or FIN was suggested to have a synergistic effect in enhancing hair growth. In another recent multicentric, randomized, sham device-controlled, double-blind clinical trial that analyzed the efficacy of lasercomb in 103 male and 122 female subjects, whole scalp treatments were given with a laser comb (trial groups) or sham device three times a week for 26 weeks. The mean terminal hair count of the target area at 26 weeks in the lasercomb-treated subjects increased significantly from baseline (ranging from 18.4 to 25.7 per $\mathrm{cm} 2$ ), compared with minimal increase noted in sham-treated subjects [103]. However, additional studies to determine the long-term effects of LLLT on hair growth and to optimize

\section{Stem cell based treatment}

Cell mediated treatments for AGA broadly include two main approaches: the direct injection of cultured stem cells (SC) or the use of cell secreted hair growth enhancing humoral factors. The premise of cell-based treatment for AGA is that even till advanced stages of AGA, the stem cell population is preserved, suggesting potential reversibility of the condition [104]. The study of the HF stem cells (HFSCs) started with the identification of epidermal SC in the HF bulge as quiescent "label retaining cells". The research of these cells emerged rapidly after the identification of bulge cell molecular markers, such as keratin 15 and CD34 in mice and CD200 in humans, which allowed the isolation and characterization of bulge cells from follicles [105]. Dermal Papillae is a unique population of mesenchymal cells that regulates formation of $\mathrm{HF}$ as well as the growth cycle. Although, DP cells were proposed as the cell-based treatment for hair loss conditions like AGA, unfortunately human DP cells are not suitable for this purpose because they cannot be obtained in necessary amounts and rapidly lose their ability to induce HF formation when cultured. During development most DP cells are derived from mesoderm, however, functionally equivalent DP cells of cephalic hair originate from neural crest (NC). In the landmark study of Gnedeva et al., human embryonic stem cells (hESCs) were directed to generate NC cells and then hair-inducing DP-like cells in culture. These hESC-derived DP-like cells (hESC-DPs) express markers typically found in adult human DP cells and are able to induce hair follicle formation when transplanted under the skin of immunodeficient nude mice [106]. The development of hESC-DPs seemingly heralds a major breakthrough towards a cell-based treatment for AGA and other hair loss disorders. Human hair folliclederived mesenchymal stem cells (HF-MSCs) are also capable of differentiating along multiple lineages. Addition of EGF and FGF to the culture media enhance cellular pluripotency. Other cell lines including epidermal keratinocytes, dermal fibroblasts and adipocytes 
have also been explored for cell-based treatment of hair loss. Recently, skin derived progenitor cells (SKPs) have been expanded in vitro from the dermis and share certain characteristics of DP cells. SKPs are highly plastic even after long-term expansion in vitro and can differentiate into multiple lineages. SKPs are also able to induce HF formation and they can be an ample source of inductive dermal cells for HF regeneration [107]. Adipose tissue-derived stem cells (ADSCs) and conditioned media of ADSCs (ADSC-CM) are reported to promote hair growth in vitro. In a recent retrospective, observational study of 27 patients with FPHL treated with ADSC-CM, application of ADSC-CM showed efficacy in treating FPHL after 12 weeks of therapy [108]. There was a significant increase in hair density as well as hair thickness, with no severe adverse reactions. The search for more robust sources of generating a pool of human HF is ongoing and hopefully, stem-cell based therapies shall occupy a prominent position in the therapeutic armamentarium of AGA.

\section{Future potential treatments that may be effective in AGA include:}

Nitric oxide (NO) gel, which has been shown to promote hair follicle formation through stem cell development, hair regeneration, hair shaft elongation and increased growth rate in rats and mice [10].

Vitamin D3: The Vitamin D receptor (VDR) is expressed in hair follicle keratinocytes during late anagen and catagen. Additionally, Vitamin D3 has also been shown to modulate Wnt10b gene expression [109]. Studies based on VD3 gene knock-out and VD3 supplementation in nude mice has revealed encouraging hair growth promoting effects of VD3 [10].

Nestin and noggin: Studies carried on patients with alopecia areata showed that middle anagen and early anagen hair follicles with growing cells were found to be nestin positive, suggesting a role of nestin-positive in the regenerating hair follicles. Noggin is an inhibitor of the bone morphogenetic protein-4 (BMP4), which physiologically induces selective arrest of anagen development in the secondary hair follicles [110]. Experimentally, the administration of noggin protein was found to induce new hair growth phase in postnatal telogen skin in vivo.

\section{Conclusion}

The exact pathogenesis of AGA remains elusive and seems to involve multiple players acting at different levels and stages. The understanding of newer pathogenetic mechanisms contributing to progressive miniaturization of hair in AGA such as the androgenmediated suppression of $\mathrm{Wnt} / \beta$-catenin pathway, follicular microinflammation, perifollicular paracrine prostaglandin imbalance, and oxidative stress have enhanced the possibility of development of targeted therapies manifold. With MNX and FIN remaining the only two US-FDA approved treatments for AGA that often do not produce desirable results, quest for such therapies and new avenues like hair follicle bioengineering was logical. Hopefully, with improved elucidation of molecular mechanisms underlying follicular miniaturization, development of more efficacious treatment options would ensue.

\section{Conflict of Interest:}

Dr Antonella Tosti has in the past received honoraria as consultant from the following companies-Incyte, Khytera, P and G, DS Laboratories, Inneov Laboratories, Polichem.
Dr Sidharth Sonthalia has in the past received honoraria as consultant from the following companies- Sun Pharmaceuticals, Cipla Externa, $\mathrm{H}$ and $\mathrm{H}$ pharmaceuticals and Glenmark. He is also on the medical advisory board of the South Asian Pigmentary Disorder Forum (SPF) of GALDERMA.

However, none of the financial associations of Dr Tosti or Dr Sonthalia had in any way been an influence on the contents of the manuscript being submitted.

\section{References}

1. Cash TF (1992) The psychological effects of androgenetic alopecia in men. J Am Acad Dermatol 26: 926-931.

2. Lee HJ, Ha SJ, Kim D, Kim HO, Kim JW (2002) Perception of men with androgenetic alopecia by women and nonbalding men in Korea: how the nonbald regard the bald. Int J Dermatol 41: 867-869.

3. Gan DC, Sinclair RD (2005) Prevalence of male and female pattern hair loss in Maryborough. J Investig Dermatol Symp Proc 10: 184-189.

4. Sinclair R (2015) Hair shedding in women: how much is too much? Br J Dermatol 173: 846-848.

5. Hoffmann R, Happle R (2000) Current understanding of androgenetic alopecia. Part I: etiopathogenesis. Eur J Dermatol 10: 319-327.

6. Trueb RM (2008) Das Haar im Alter. Haut 4: 152-155.

7. Singal A, Sonthalia S, Verma P (2013) Female pattern hair loss. Indian J Dermatol Venereol Leprol 79: 626-640.

8. Mahé YF, Michelet JF, Billoni N, Jarrousse F, Buan B, et al. (2000) Androgenetic alopecia and microinflammation. Int J Dermatol 39: 576-584.

9. Sonthalia S, Sahaya K, Arora R, Singal A, Srivastava A, et al. (2015) Nocebo effect in Dermatology. Indian J Dermatol Venereol Leprol 81: 242-250.

10. Valente Duarte de Sousa IC, Tosti A (2013) New investigational drugs for androgenetic alopecia. Expert Opin Investig Drugs 22: 573-589.

11. Leirós GJ, Attorresi AI, Balañá ME (2012) Hair follicle stem cell differentiation is inhibited through cross-talk between Wnt/ $\beta$-catenin and androgen signalling in dermal papilla cells from patients with androgenetic alopecia. Br J Dermatol 166: 1035-1042.

12. Fu J, Hsu W (2013) Epidermal Wnt controls hair follicle induction by orchestrating dynamic signaling crosstalk between the epidermis and dermis. J Invest Dermatol 133: 890-898.

13. Kishimoto J, Burgeson RE, Morgan BA (2000) Wnt signaling maintains the hair-inducing activity of the dermal papilla. Genes Dev 14: 1181-1185.

14. Chen D, Jarrell A, Guo C, Lang R, Atit R (2012) Dermal $\beta$-catenin activity in response to epidermal Wnt ligands is required for fibroblast proliferation and hair follicle initiation. Development 139: 1522-1533.

15. Shimizu H, Morgan BA (2004) Wnt signaling through the beta-catenin pathway is sufficient to maintain, but not restore, anagen-phase characteristics of dermal papilla cells. J Invest Dermatol 122: 239-245.

16. Schmidt-Ullrich R, Paus R (2005) Molecular principles of hair follicle induction and morphogenesis. Bioessays 27: 247-261.

17. Lee SH, Yoon J, Shin SH, Zahoor M, Kim HJ, et al. (2012) Valproic acid induces hair regeneration in murine model and activates alkaline phosphatase activity in human dermal papilla cells. PLoS One 7: e34152.

18. Jo SJ, Choi SJ, Yoon SY, Lee JY, Park WS, et al. (2013) Valproic acid promotes human hair growth in in vitro culture model. J Dermatol Sci 72: 16-24.

19. Zimber MP, Ziering C, Zeigler F, Hubka M, Mansbridge JN, et al. (2011) Hair regrowth following a Wnt- and follistatin containing treatment: safety and efficacy in a first-in-man phase 1 clinical trial. J Drugs Dermatol 10: 1308-1312.

20. Whiting DA (1993) Diagnostic and predictive value of horizontal sections of scalp biopsy specimens in male pattern androgenetic alopecia. J Am Acad Dermatol 28: 755-763. 
21. Trüeb RM (2009) Oxidative stress in ageing of hair. Int J Trichology 1: 6-14.

22. Sakr FM, Gado AM, Mohammed HR, Adam AN (2013) Preparation and evaluation of a multimodal minoxidil microemulsion versus minoxidil alone in the treatment of androgenic alopecia of mixed etiology: a pilot study. Drug Des Devel Ther 30: 413-423.

23. Garza LA, Liu Y, Yang Z, Alagesan B, Lawson JA, et al. (2012) Prostaglandin D2 inhibits hair growth and is elevated in bald scalp of men with androgenetic alopecia. Sci Transl Med 4: 126ra34.

24. Colombe L, Michelet JF, Bernard BA (2008) Prostanoid receptors in anagen human hair follicles. Exp Dermatol 17: 63-72.

25. Pettipher R, Vinall SL, Xue L, Speight G, Townsend ER, et al. (2012) Pharmacologic profile of OC000459, a potent, selective, and orally active D prostanoid receptor 2 antagonist that inhibits mast cell-dependent activation of T helper 2 lymphocytes and eosinophils. J Pharmacol Exp Ther 340: 473-482.

26. Jones RL, Giembycz MA, Woodward DF (2009) Prostanoid receptor antagonists: development strategies and therapeutic applications. Br J Pharmacol 158: 104-145.

27. Naito A, Midorikawa T, Yoshino T, Ohdera M (2008) Lipid peroxides induce early onset of catagen phase in murine hair cycles. Int J Mol Med 22: 725-729.

28. Bahta AW, Farjo N, Farjo B, Philpott MP (2008) Premature senescence of balding dermal papilla cells in vitro is associated with p16(INK4a) expression. J Invest Dermatol 128: 1088-1094.

29. Loing E, Lachance R, Ollier V, Hocquaux M (2013) A new strategy to modulate alopecia using a combination of two specific and unique ingredients. J Cosmet Sci 64: 45-58.

30. Messenger AG, Elliott K, Temple A, Randall VA (1991) Expression of basement membrane proteins and interstitial collagens in dermal papillae of human hair follicles. J Invest Dermatol 96: 93-97.

31. Randall VA, Thornton MJ, Hamada K, Messenger AG (1994) Androgen action in cultured dermal papilla cells from human hair follicles. Skin Pharmacol 7: 20-26.

32. Hajem N, Chapelle A, Bignon J, Pinault A, Liu JM, et al. (2013) The regulatory role of the tetrapeptide AcSDKP in skin and hair physiology and the prevention of ageing effects in these tissues--a potential cosmetic role. Int J Cosmet Sci 35: 286-298.

33. Caserini M, Radicioni M, Leuratti C, Annoni O, Palmieri R (2014) A novel finasteride $0.25 \%$ topical solution for androgenetic alopecia: pharmacokinetics and effects on plasma androgen levels in healthy male volunteers. Int J Clin Pharmacol Ther 52: 842-849.

34. Chandrashekar BS, Nandhini T, Vasanth V, Sriram R, Navale S (2015) Topical minoxidil fortified with finasteride: An account of maintenance of hair density after replacing oral finasteride. Indian Dermatol Online J 6: 17-20.

35. Clark RV, Hermann DJ, Cunningham GR, Wilson TH, Morrill BB, et al. (2004) Marked suppression of dihydrotestosterone in men with benign prostatic hyperplasia by dutasteride, a dual 5alpha-reductase inhibitor. J Clin Endocrinol Metab 89: 2179-2184.

36. Olsen EA, Hordinsky M, Whiting D, et al. (2006). The importance of dual 5alpha-reductase inhibition in the treatment of male pattern hair loss: results of a randomized placebo-controlled study of dutasteride versus finasteride. J Am Acad Dermatol 55: 1014-1023.

37. Olszewska M, Rudnicka L (2005) Effective treatment of female androgenic alopecia with dutasteride. J Drugs Dermatol 4: 637-640.

38. Boersma IH, Oranje AP, Grimalt R, Iorizzo M, Piraccini BM, et al. (2014) The effectiveness of finasteride and dutasteride used for 3 years in women with androgenetic alopecia. Indian J Dermatol Venereol Leprol 80: 521-525.

39. Chatterjee S, Agrawala SK (2003). Saw palmetto (Serenoa repens) in androgenic alopecia: An effective phytotherapy. Natural Product Radiance 2: 302-305.
40. Wilt TJ, Ishani A, Stark G, MacDonald R, Lau J, et al. (1998) Saw palmetto extracts for treatment of benign prostatic hyperplasia: a systematic review. JAMA 280: 1604-1609.

41. Prager N, Bickett K, French N, Marcovici G (2002). A randomized, double-blind, placebo-controlled trial to determine the effectiveness of botanically derived inhibitors of 5-alpha-reductase in the treatment of androgenetic alopecia. J Altern Complement Med 8: 143-152.

42. Rossi A, Mari E, Scarno M, Garelli V, Maxia C, et al. (2012) Comparitive effectiveness of finasteride vs Serenoa repens in male androgenetic alopecia: a two-year study. Int J Immunopathol Pharmacol 25: 1167-1173.

43. McElwee KJ, Shapiro JS (2012) Promising therapies for treating and/or preventing androgenic alopecia. Skin Therapy Lett 17: 1-4.

44. Brzezinska-Wcislo L (2003) [Assessment of efficacy of Diane-35 in androgenetic feminine alopecia]. Wiad Lek 56: 202-205.

45. Peereboom-Wynia JD, van der Willigen AH, van Joost T, Stolz E (1989) The effect of cyproterone acetate on hair roots and hair shaft diameter in androgenetic alopecia in females. Acta Derm Venereol 69: 395-398.

46. Sinclair R, Wewerinke M, Jolley D (2005) Treatment of female pattern hair loss with oral antiandrogens. Br J Dermatol 152: 466-473.

47. Yazdabadi A, Sinclair R (2011) Treatment of female pattern hair loss with the androgen receptor antagonist flutamide. Australas J Dermatol 52: 132-134.

48. Carmina E, Lobo RA (2003) Treatment of hyperandrogenic alopecia in women. Fertil Steril 79: 91-95.

49. Jo SJ, Shin H, Park YW, Paik SH, Park WS, et al. (2014). Topical valproic acid increases the hair count in male patients with androgenetic alopecia: a randomized, comparative, clinical feasibility study using phototrichogram analysis. J Dermatol 41: 285-291.

50. Cegielski M, Izykowska I, Chmielewska M, Dziewiszek W, Bochnia M, et al. (2013) Characteristics of MIC-1 antlerogenic stem cells and their effect on hair growth in rabbits. In Vivo 27: 97-106.

51. Toyoshima KE, Asakawa K, Ishibashi N, Toki H, Ogawa M, et al. (2012) Fully functional hair follicle regeneration through the rearrangement of stem cells and their niches. Nat Commun 3: 784.

52. Levy LL, Emer JJ (2013) Female pattern alopecia: current perspectives. Int J Womens Health 5: 541-556.

53. Blume-Peytavi U, Lönnfors S, Hillmann K, Garcia Bartels N (2012). A randomized double-blind placebo-controlled pilot study to assess the efficacy of a 24 -week topical treatment by latanoprost $0.1 \%$ on hair growth and pigmentation in healthy volunteers with androgenetic alopecia. J Am Acad Dermatol 66: 794-800.

54. Emer JJ, Stevenson ML, Markowitz O (2011) Novel treatment of femalepattern androgenetic alopecia with injected bimatoprost $0.03 \%$ solution. J Drugs Dermatol 10: 795-798.

55. Lassus A, Eskelinen E (1992) A comparative study of a new food supplement, ViviScal, with fish extract for the treatment of hereditary androgenic alopecia in young males. J Int Med Res 20: 445-453.

56. Glynis A (2012) A Double-blind, Placebo-controlled Study Evaluating the Efficacy of an Oral Supplement in Women with Self-perceived Thinning Hair. J Clin Aesthet Dermatol 5: 28-34.

57. Thom E (2001) Efficacy and tolerability of Hairgain in individuals with hair loss: a placebo-controlled, double-blind study. J Int Med Res 29: 2-6.

58. Pereira JM (1997) Uso do extrato de protefnas e polissacarfdeos de origem marinha no tratamento da alopecia androgenetica. Rev Bras Med 53: $144-155$

59. Ablon G (2015) A 3-month, randomized, double-blind, placebocontrolled study evaluating the ability of Viviscal extra-strength formulation to promote hair growth and decrease shedding in women with self-perceived thinning hair. Dermatol Res Pract 8: 41-57.

60. Hornfeldt CS, Holland M, Bucay VW, Roberts WE, Waldorf HA, et al (2015) The Safety and Efficacy of a Sustainable Marine Extract for the Treatment of Thinning Hair: A Summary of New Clinical Research and Results from a Panel Discussion on the Problem of Thinning Hair and Current Treatments. J Drugs Dermatol 14: s15-22. 
61. Eppley BL, Pietrzak WS, Blanton M (2006) Platelet-rich plasma: a review of biology and applications in plastic surgery. Plast Reconstr Surg 118: $147 \mathrm{e}-159 \mathrm{e}$.

62. Gkini MA, Kouskoukis AE1, Tripsianis G, Rigopoulos D, Kouskoukis K (2014) Study of platelet-rich plasma injections in the treatment of androgenetic alopecia through an one-year period. J Cutan Aesthet Surg 7:213-219.

63. Gentile P, Garcovich S, Bielli A, Scioli MG, Orlandi A, et al. (2015) The Effect of Platelet-Rich Plasma in Hair Regrowth: A Randomized PlaceboControlled Trial. Stem Cells Transl Med 4: 1317-1323.

64. Dhurat R, Sukesh M (2014) Principles and Methods of Preparation of Platelet-Rich Plasma: A Review and Author's Perspective. J Cutan Aesthet Surg 7: 189-197.

65. Jeong K, Lee YJ, Kim JE, Park YM, Kim BJ, et al. (2012) Repeated microneedle stimulation induce the enhanced expression of hair-growthrelated genes. Int J Trichology 12: 117.

66. Kim BJ, Lim YY, Kim HM, Lee YW, Won CH, et al. (2012) Hair follicle regeneration in mice after wounding by microneedle roller. Int $\mathrm{J}$ Trichology 4: 117.

67. Dhurat R, Sukesh M, Avhad G, Dandale A, Pal A, et al. (2013) A randomized evaluator blinded study of effect of microneedling in androgenetic alopecia: a pilot study. Int J Trichology 5: 6-11.

68. Severino D, Zorn TM, Micke GA, Costa AC, Silva JR, et al. (2011) Diguanoside tetraphosphate $(\mathrm{Gp} 4 \mathrm{G})$ is an epithelial cell and hair growth regulator. J Cosmet Sci 62: 469-482.

69. Zempleni J, Hassan YI, Wijeratne SS (2008) Biotin and biotinidase deficiency. Expert Rev Endocrinol Metab 3: 715-724.

70. Schulpis KH, Karikas GA, Tjamouranis J, Regoutas S, Tsakiris S (2001) Low serum biotinidase activity in children with valproic acid monotherapy. Epilepsia 42: 1359-1362.

71. Castro-Gago M, Gómez-Lado C, Eirís-Puñal J, Díaz-Mayo I, CastiñeirasRamos DE (2010) Serum biotinidase activity in children treated with valproic acid and carbamazepine. J Child Neurol 25: 32-35.

72. Famenini S, Goh C (2014) Evidence for supplemental treatments in androgenetic alopecia. J Drugs Dermatol 13: 809-812.

73. Plonka PM, Handjiski B, Popik M, Michalczyk D, Paus R (2005) Zinc as an ambivalent but potent modulator of murine hair growth in vivopreliminary observations. Exp Dermatol 14: 844-853.

74. Rushton DH (2002) Nutritional factors and hair loss. Clin Exp Dermatol 27: 396-404.

75. Park H, Kim CW, Kim SS, Park CW (2009) The therapeutic effect and the changed serum zinc level after zinc supplementation in alopecia areata patients who had a low serum zinc level. Ann Dermatol 21: 142-146.

76. Arnaud J, Beani JC, Favier AE, Amblard P (1995) Zinc status in patients with telogen defluvium. Acta Derm Venereol 75: 248-249.

77. Kil MS, Kim CW, Kim SS (2013) Analysis of serum zinc and copper concentrations in hair loss. Ann Dermatol 25: 405-409.

78. Stamatiadis D, Bulteau-Portois MC, Mowszowicz I (1988) Inhibition of 5 alpha-reductase activity in human skin by zinc and azelaic acid. $\mathrm{Br} \mathrm{J}$ Dermatol 119: 627-632.

79. Le Floc'h C, Cheniti A, Connétable S, Piccardi N, Vincenzi C, et al. (2015) Effect of a nutritional supplement on hair loss in women. J Cosmet Dermatol 14: 76-82.

80. Lengg N, Heidecker B, Seifert B, Trüeb RM (2007) Dietary supplement increases anagen hair rate in women with telogen effluvium: Results of a double-blind placebo-controlled trial. Therapy 4: 59-65.

81. Candiani C, Bestetti A (2010). Clinical evaluation of a trichological phytoextract in most frequent forms of hair loss: Results of a metaanalysis study. European Bulletin of Drug Research 18: 9-17.

82. Gori G, Lucheroni MT, Candiani C, Bestetti A (2010) Clinical evaluation of a trichological phytoextract inandrogenetic alopecia. European Bulletin of Drug Research 18: 1-4.

83. Fischer TW, Hipler UC, Elsner P (2007) Effect of caffeine and testosterone on the proliferation of human hair follicles in vitro. Int J Dermatol 46: 27-35.
84. Fischer TW, Herczeg-Lisztes E, Funk W, Zillikens D, Bíró T, et al. (2014) Differential effects of caffeine on hair shaft elongation, matrix and outer root sheath keratinocyte proliferation, and transforming growth factorß2/insulin-like growth factor-1-mediated regulation of the hair cycle in male and female human hair follicles in vitro. Br J Dermatol 171: 1031-1043.

85. Slominski A, Pisarchik A, Zbytek B, Tobin DJ, Kauser S, et al. (2003) Functional activity of serotoninergic and melatoninergic systems expressed in the skin. J Cell Physiol 196: 144-153.

86. Fischer TW, Scholz G, Knöll B, Hipler UC, Elsner P (2002) Melatonin suppresses reactive oxygen species in UV-irradiated leukocytes more than vitamin C and trolox. Skin Pharmacol Appl Skin Physiol 15: 367-373.

87. Fischer TW, Scholz G, Knöll B, Hipler UC, Elsner P (2004) Melatonin suppresses reactive oxygen species induced by UV irradiation in leukocytes. J Pineal Res 37: 107-112.

88. Fischer TW, Slominski A, Tobin DJ, Paus R (2008) Melatonin and the hair follicle. J Pineal Res 44: 1-15.

89. Fischer TW (2009) [The influence of melatonin on hair physiology]. Hautarzt 60: 962-972.

90. Fischer TW, Fischer A, Knöll B, Hipler UC, Elsner P (2000). Melatonin in low doses enhances in vitro human hair follicle proliferation and inhibits hair growth in high doses. Arch Derm Res 292: 147.

91. Fischer TW, Trüeb RM, Hänggi G, Innocenti M, Elsner P (2012) Topical melatonin for treatment of androgenetic alopecia. Int J Trichology 4: 236-245.

92. Takahashi H, Suzuki Y, Miyauchi Y, Hashimoto Y, Ishida-Yamamoto A, et al. (2004). Roxithromycin decreases ultraviolet B irradiation-induced reactive oxygen intermediates production and apoptosis of keratinocytes. J Dermatol Sci 34: 25-33.

93. Inui S, Nakajima T, Fukuzato Y, Fujimoto N, Chang C, et al. (2001) Potential anti-androgenic activity of roxithromycin in skin. J Dermatol Sci 27: 147-151.

94. Ito T, Fukamizu H, Ito N, Seo N, Yagi H, et al. (2009) Roxithromycin antagonizes catagen induction in murine and human hair follicles: implication of topical roxithromycin as hair restoration reagent. Arch Dermatol Res 301: 347-355.

95. Moreno-Arias G, Castelo-Branco C, Ferrando J (2002) Paradoxical effect after IPL photoepilation. Dermatol Surg 28: 1013-1016.

96. Bernstein EF (2005) Hair growth induced by diode laser treatment. Dermatol Surg 31: 584-586.

97. Munck A, Gavazzoni MF, Trüeb RM (2014) Use of low-level laser therapy as monotherapy or concomitant therapy for male and female androgenetic alopecia. Int J Trichology 6: 45-49.

98. Leavitt M, Charles G, Heyman E, Michaels D (2009) HairMax LaserComb laser phototherapy device in the treatment of male androgenetic alopecia: A randomized, double-blind, sham devicecontrolled, multicentre trial. Clin Drug Investig 29: 283-292.

99. Avram MR, Rogers NE (2009) The use of low-level light for hair growth: part I. J Cosmet Laser Ther 11: 110-117.

100. Avram MR, Leonard RT Jr, Epstein ES, Williams JL, Bauman AJ (2007) The current role of laser/light sources in the treatment of male and female pattern hair loss. J Cosmet Laser Ther 9: 27-28.

101. Lanzafame RJ, Blanche RR, Bodian AB, Chiacchierini RP, FernandezObregon A, et al. (2013) The growth of human scalp hair mediated by visible red light laser and LED sources in males. Lasers Surg Med 45: 487-495.

102. Kim H, Choi JW, Kim JY, Shin JW, Lee SJ, et al. (2013) Low-level light therapy for androgenetic alopecia: a 24-week, randomized, double-blind, sham device-controlled multicenter trial. Dermatol Surg 39: 1177-1183.

103. Jimenez JJ, Wikramanayake TC, Bergfeld W, Hordinsky M, Hickman JG, et al. (2014) Efficacy and safety of a low-level laser device in the treatment of male and female pattern hair loss: a multicenter, randomized, sham device-controlled, double-blind study. Am J Clin Dermatol 15: 115-127.

104. Garza LA, Yang CC, Zhao T, Blatt HB, Lee M, et al. (2011) Bald scalp in men with androgenetic alopecia retains hair follicle stem cells but lacks 
Citation: Sonthalia S, Daulatabad D, Tosti A (2016) Hair Restoration in Androgenetic Alopecia: Looking Beyond Minoxidil, Finasteride and Hair Transplantation. J Cosmo Trichol 2: 1000105. doi:10.4172/2471-9323.1000105

Page 13 of 13

CD200-rich and CD34-positive hair follicle progenitor cells. J Clin Invest 121: 613-622.

105. Mokos ZB, Mosler EL (2014) Advances in a rapidly emerging field of hair follicle stem cell research. Coll Antropol 38: 373-378.

106. Gnedeva K, Vorotelyak E, Cimadamore F, Cattarossi G, Giusto E, et al. (2015) Derivation of hair-inducing cell from human pluripotent stem cells. PLoS One 10: e0116892.

107. Biernaskie J, Paris M, Morozova O, Fagan BM, Marra M, et al. (2009) SKPs derive from hair follicle precursors and exhibit properties of adult dermal stem cells. Cell Stem Cell 5: 610-623.
108. Shin H, Ryu HH, Kwon O, Park BS, Jo SJ (2015) Clinical use of conditioned media of adipose tissue-derived stem cells in female pattern hair loss: a retrospective case series study. Int J Dermatol 54: 730-735.

109. Yoshizawa T, Handa Y, Uematsu Y, Takeda S, Sekine K, et al. (1997) Mice lacking the vitamin $\mathrm{D}$ receptor exhibit impaired bone formation, uterine hypoplasia and growth retardation after weaning. Nat Genet 16: 391-396.

110. Phansalkar K, Patil N, Ramani A (2014) A brief overview of the role of drugs and novel methodologies on the stability and growth of hair follicles: an approach towards hair regeneration. J Clin Diagn Res 8: 331 . 